http://jmscr.igmpublication.org/home/

ISSN (e)-2347-176x ISSN (p) 2455-0450

crossref DOI: https://dx.doi.org/10.18535/jmscr/v7i7.108

Journal Of Medical Science And Clinical Research

IGM Publication

An Official Publication of IGM Publication

\title{
Assessment of knowledge and practice regarding menstrual hygiene among school going adolescent girls of Jaipur city
}

\author{
Authors \\ Nikita Sharma, Rekha Shekhawat*, Kusum Gaur, K K Meena, G L Meena, \\ Monika Rathore, Mahesh Verma, Dilip Raj, Rajeev Yadav, Suresh Kewalramani \\ Corresponding Author \\ Rekha Shekhawat
}

\begin{abstract}
Introduction: There is lack of information on the process of menstruation, the physical and psychological changes associated with puberty and proper requirements for managing menstruation. Hence this community based study was carried out with the objective to assess the level of knowledge and practice regarding menstrual hygiene among school going adolescent girls.

Methodology: A descriptive, cross sectional study was conducted among 996 adolescent girls of senior secondary schools of Jaipur city.

Results: It was evident that $80.72 \%$ participants were aware about menstruation before their menarche and the most important sources of information were mothers (67.77\%).Participants who were aware of the fact that menstruation is a normal process in which source of bleeding is uterus was 60.14\%.Majority (68.07\%) used sanitary pad as absorbent material. $34 \%$ changed absorbent every 5-6 hours. $51.70 \%$ of participants cleaned external genital area twice a day. Majority (75.56\%) of participants discard the pad in dustbin after wrapping in paper.

Conclusions: The present study reveals that only $68.07 \%$ participants use sanitary pads. There is strong need to improvise and promote good menstrual hygiene knowledge and practices among adolescent girls. Improving mother's knowledge on menstrual hygiene management can go a long way in improving menstrual hygiene practice.

Keywords: Adolescent girls, Menarche, Menstruation, Menstrual Hygiene.
\end{abstract}

\section{Introduction}

Adolescence is a transitional phase of growth and development between childhood and adulthood. The World Health Organization (WHO) defines an adolescent as any person between ages 10 and 19 years $^{(1)}$. India is the home to 243 million adolescents contributing to one fifth $(21.4 \%)$ of India's Population and Adolescent girls constitute to 47 percent of total adolescent population ${ }^{(2)}$. Adolescence is understood as a stage in the lives of females, which indicates their transition from girlhood to womanhood. This transitional period is marked with the onset of menarche, an important biological milestone. ${ }^{(3)}$. Menarche is the first menstruation of a girl. Menarche is the first menstruation of a girl.It occurs at the age of 1213 years, although it may occur as early as 10 years or as late as 16 years. The age of menarche is between 10-16 years (average age 13.5years) in India $^{(4)}$. Globally about $52 \%$ of the female 
population is of reproductive age, meaning menstruation is part of their normal life and menstrual hygiene is therefore an essential part of basic hygienic practices ${ }^{(5)}$. Menstrual hygiene, which refers to the effective management of menstrual bleeding by women and girls, is an important aspect of reproductive health, which if not handled appropriately can cause infections of the urinary tract, pelvic inflammatory diseases and vaginal thrush, as well as bad odor, soiled garments and ultimately shame, leading to infringement on the girl's dignity ${ }^{(6)}$. Hence, targeting school girls at the time of adolescence is an appropriate strategy since it is the time when most of them are curious about their bodily changes and also active learning phase takes place. Even in urban areas due to lack of time given by parents, hesitation of teachers girls have incomplete knowledge regarding menstruation. Thus, present study was conducted with the aim to explore the prevailing knowledge and practices of menstrual hygiene among school going adolescent girls (10 -19 years) of Jaipur city.

\section{Material and Methods}

Study Area: Senior Secondary schools of Jaipur City.

Study Type: This is a community based descriptive type of observational study which was conducted on adolescent female students (10-19 years) of Jaipur city.

Study Design: Cross sectional study design.

Study Period: After getting approval from the institutional research review board and Ethical committee, plan of study was executed. Data collection for this study was carried out from $1^{\text {st }}$ July 2017 to $10^{\text {th }}$ April, 2018.

Study Universe: Female students of age group 10- 19 years studying in class $6^{\text {th }}-12^{\text {th }}$ of randomly selected schools of Jaipur city.

Sample Size: The sample size calculated was 793 at $95 \%$ confidence interval and $7 \%$ relative error to verify the expected minimum $50.8 \%{ }^{(7)}$ of prevalence of adolescent girls practicing the use of sanitary pads during menstruation. It is enhanced to 1000 , to cover the expected $20 \%$ non response.

Study Tool: Pre designed and pre tested structured questionnaire having following parts:

a) Section A-Socio demographic Proforma.

b) Section B-Questions for assessment of menstrual pattern including age of menarche, cycle length, duration of flow, menstruation related physical problems.

c) Section C-Questionnaire regarding knowledge of menstrual hygiene.

d) Section D-Questionnaire regarding practice of menstrual hygiene.

\section{Inclusion Criteria}

- Female students of 10 to 19 years studying in Government and Private senior secondary schools (Girls and CoEducational) having $\geq 500$ students $\mathrm{f}$ Jaipur City

- Female students present on the day of study.

- Female students who had attained menarche.

\section{Exclusion Criteria}

- Those whose Principal/school authorities did not give consent.

- Female students who had not attained menarche.

- Female students who were absent on the day of study.

\section{Sampling Technique}

A complete list of Senior Secondary; Government and Private Schools of Jaipur city; with $\geq 500$ students (girls or co-educational) was procured from Department of Education, Jaipur. All schools in each zone of the city (East, West, North and South) were categorized into government and private schools. One school each of government and private category from each zone (East, West, North and South zone) was selected by simple random sampling technique i.e. 8 schools in total. Permission to collect information was taken from District Education officer. Permission was taken 
from principals of the selected School. If permission from selected school authority was not granted then it was replaced by the next school in the list in same category.125 female students studying in class $6-12^{\text {th }}$ from each school were randomly selected to cover the sample size of 1000.Hence 18 randomly selected female students from each class $\left(6^{\text {th }}\right.$ to $\left.12^{\text {th }}\right)$ were included .In case there was more than one section in a class , section was selected by chit in box method and 18 female students were selected by simple random method from the list of class roll numbers by using computer generated random numbers .If the selected female had not attained menarche than next roll number female student was selected All randomly selected eligible female students were asked to fill the pre-designed, pre-tested, structured Knowledge and Practice questionnaire after explaining them the purpose of study and promise anonymity. In co -educational schools, authorities were requested to make proper arrangements to ensure privacy for female students at the time of data collection. This was followed by a two way discussion with study participants in presence of school staff so as to improve their knowledge and practice regarding Menstrual Hygiene Management. Data was summarised in MS excel worksheet. Continuous data was summarized in form of mean and SD and analysed and Countable Data was expressed in form of proportions.

\section{Results}

Among 996 adolescent girls majority of the participants were between 13-15 years, major group belonged to Hindu religion. Proportion in upper middle class and lower middle class found to be $42.27 \%$ and $31.73 \%$ respectively. $68.07 \%$ participants were living in a nuclear family while $31.92 \%$ were living in joint family (Table 1).Mean age of menarche of the respondents was $12.86 \pm 0.933$ years (Figure 1). Majority of the participants $(80.72 \%)$ were aware about menstruation before the attainment of menarche (Figure 2). In majority (67.77\%), mothers provided them the necessary information related to menstruation followed by elder sisters (18.17\%), school teachers (17.67\%), friends $(10.64 \%)$ and media $(9.13 \%)$. (Figure 3) .Majority of girls reported 3-5 days duration of menstrual blood flow $.50 .30 \%$ had 25-30 days cycle. Majority of girls $(69.37 \%)$ faced the problem of dysmenorrhea followed by backache (17.87\%) and nausea, vomiting (11.94\%). (Table 2) $60.14 \%$ girls knew that menstruation is a normal process in which source of blood is uterus. Most $(60.04 \%)$ of them were aware of the fact that menstrual hygiene includes choosing best hygiene products, bathing and care of vulva and vagina. $87.85 \%$ of girls had correct knowledge that readymade sanitary pads are the best absorbent to be used during menstruation (Table 3). However in practice only $68.07 \%$ participants used sanitary pad as absorbent material. $34.53 \%$ participants reported that they changed pad/cloth every 5-6 hours Majority of participants (95.96\%) bath daily during menstruation. $51.70 \%$ participants cleaned external genital area twice a day.75.56\% of participants followed the correct practice of discarding the pad in dustbin after wrapping in paper. (Table 4)

Table 1 Socio-demographic distribution of study population $(\mathrm{N}=996)$

\begin{tabular}{|l|l|}
\hline Variables & Number (\%) \\
\hline Age Group(in Years) & $161(16.16)$ \\
10-12years & $436(43.77)$ \\
13-15 years & $399(40.06)$ \\
16-19years & \\
Religion & $929(93.27)$ \\
Hindu & $52(5.22)$ \\
Muslim & $6(0.60)$ \\
Sikh & $9(0.90)$ \\
Others & \\
Socio Economic Status & $29(2.91)$ \\
Upper class & $421(42.27)$ \\
Upper-Middle class & $316(31.73)$ \\
Lower-Middle class & $220(22.09)$ \\
Upper-Lower class & $10(1)$ \\
Lower class & \\
Type of family & $678(68.07)$ \\
Nuclear & $318(31.92)$ \\
Joint & \\
\hline
\end{tabular}


Table 2 Distribution of study population according to their menstrual characteristics

\begin{tabular}{|lc|}
\hline Menstrual Pattern & Number $(\%)$ \\
\hline Normal duration of menstrual flow & \\
1-3 days & $223(22.46)$ \\
3-5 days & $445(44.67)$ \\
5-7 days & $257(25.88)$ \\
More than 7 days & $71(7.15)$ \\
Menstrual cycle in days & \\
$20-25$ & $191(19.41)$ \\
$25-30$ & $501(50.30)$ \\
30-35 & $236(23.69)$ \\
More than 35 & $68(6.91)$ \\
Physical problems during menstruation** & \\
Dysmenorrhea & $691(69.37)$ \\
Nausea and Vomiting & $119(11.94)$ \\
Breast tenderness & $89(8.93)$ \\
Backache & $178(17.87)$ \\
Any other & $91(9.13)$ \\
No complaint & $104(10.44)$ \\
\hline
\end{tabular}

*Multiple answers

Table 3 Distribution of study population as per knowledge regarding menstruation and menstrual hygiene

\begin{tabular}{|l|l|}
\hline Items & Number(\%) \\
\hline Knowledge about Menstruation Process & $599(60.14)$ \\
Normal process in which source of menstrual blood is uterus. & $197(19.77)$ \\
Normal process in which source of menstrual blood is urinary system. & $15(1.50)$ \\
Abnormal process which is not necessary. & $185(18.50)$ \\
Do Not Know. & \\
Knowledge on Menstrual Hygiene & $598(60.04)$ \\
Choosing best hygiene products, bathing and care of vulva and vagina \\
during menstruation. & $94(9.43)$ \\
Only cleaning of genitalia. & $162(16.26)$ \\
Only changing of pads. & $142(14.25)$ \\
Do not Know. & \\
Best absorbent to be used & $875(87.85)$ \\
Sanitary Pad & $51(5.12)$ \\
New Cloth & $29(2.91)$ \\
Old Cloth & $41(4.11)$ \\
Do Not Know &
\end{tabular}

Table 4 Menstrual Hygiene Practices

\begin{tabular}{|l|l|}
\hline Items & Frequency(\%) \\
\hline Type of absorbent used & $678(68.07)$ \\
Sanitary Pad & $135(13.55)$ \\
New Cloth & $63(6.32)$ \\
Old Cloth & $120(12.04)$ \\
Any of the above as per availability & \\
Frequency of changing pad & $316(31.72)$ \\
Twice a day & $57(5.72)$ \\
Once in a day & $279(28.01)$ \\
Whenever needed & $344(34.53)$ \\
Every 5-6 hours & \\
Frequency of taking bath & $956(95.98)$ \\
Daily & $27(2.71)$ \\
On first day and last day only & $10(1.00)$ \\
On last day only & $3(0.30)$ \\
No bathing & \\
Frequency of cleaning external genitalia & $190(19.07)$ \\
Once & $515(51.70)$ \\
Twice & $291(29.21)$ \\
3 or more than 3 times & \\
Disposal of Pads & $603(75.56)$ \\
Discarding in dustbin after wrapping in paper & $101(12.65)$ \\
Discarding in dustbin without wrapping in paper & $58(7.26)$ \\
Flushing down in toilet & $36(4.51)$ \\
Throw in open spaces & \\
\hline
\end{tabular}




\section{JMSCR Vol||07||Issue ||07||Page 615-623||July}

Figure 1 Age of participants at the time of menarche $(\mathrm{N}=996)$

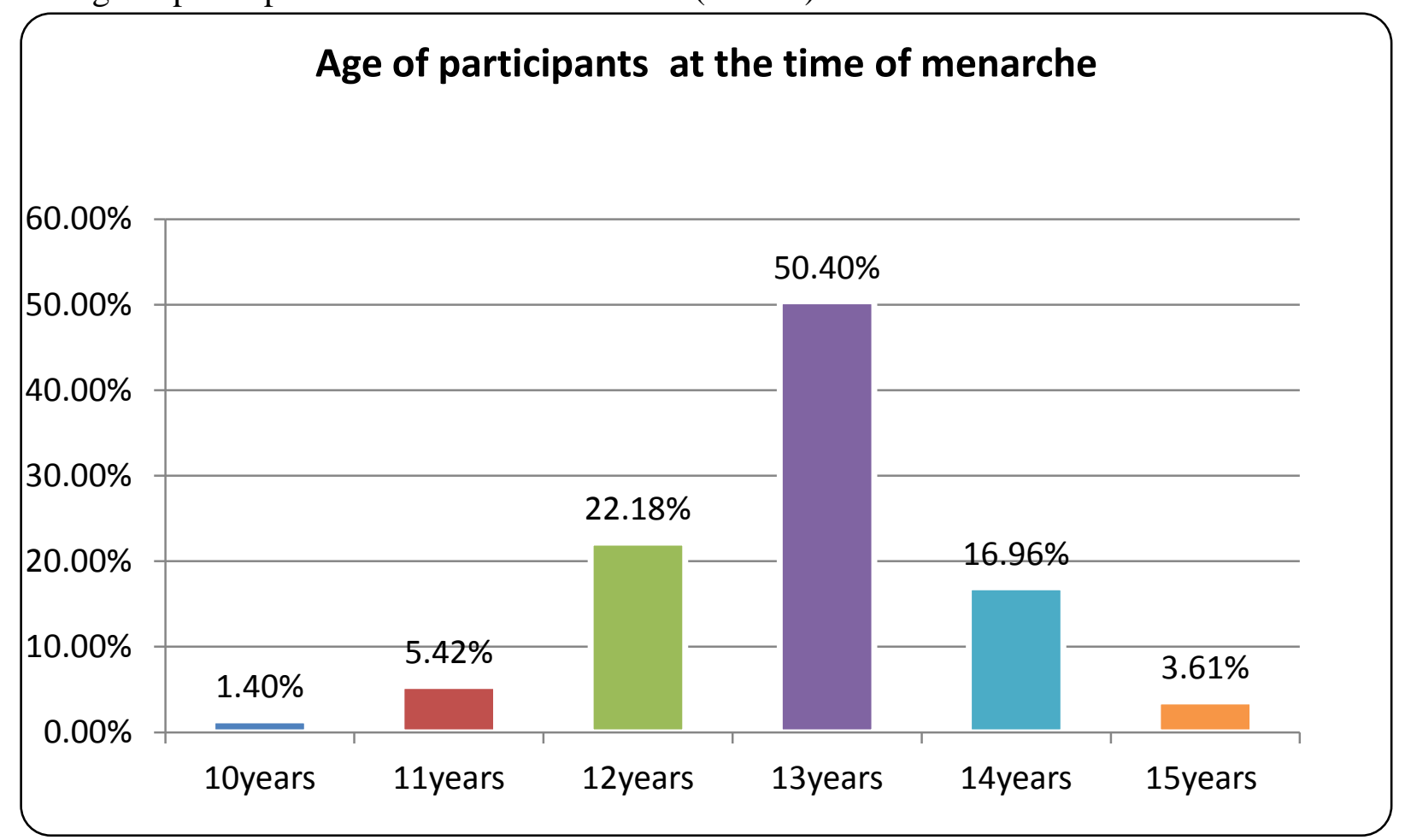

Figure 2 Distribution of study population as per their prior knowledge regarding menstruation (N=996)

\section{Distribution of study population as per their prior knowledge regarding menstruation}

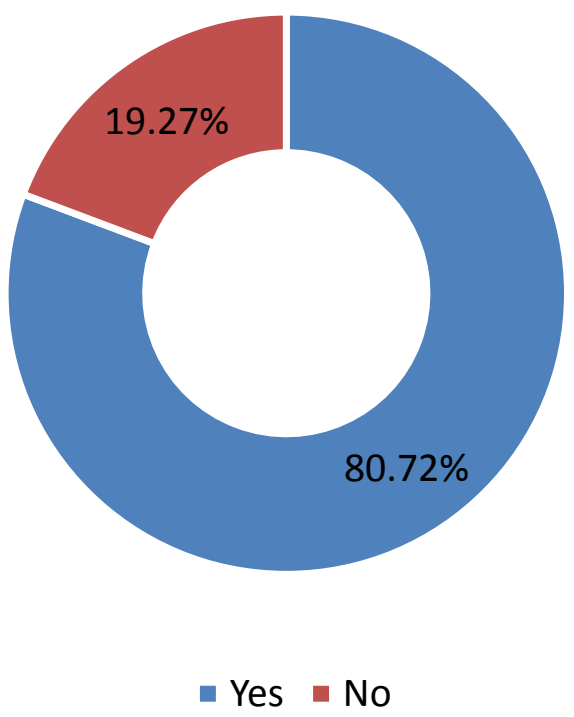


Figure 3 Distribution of study population as per their source of necessary information regarding menstruation: $(\mathrm{N}=996)$

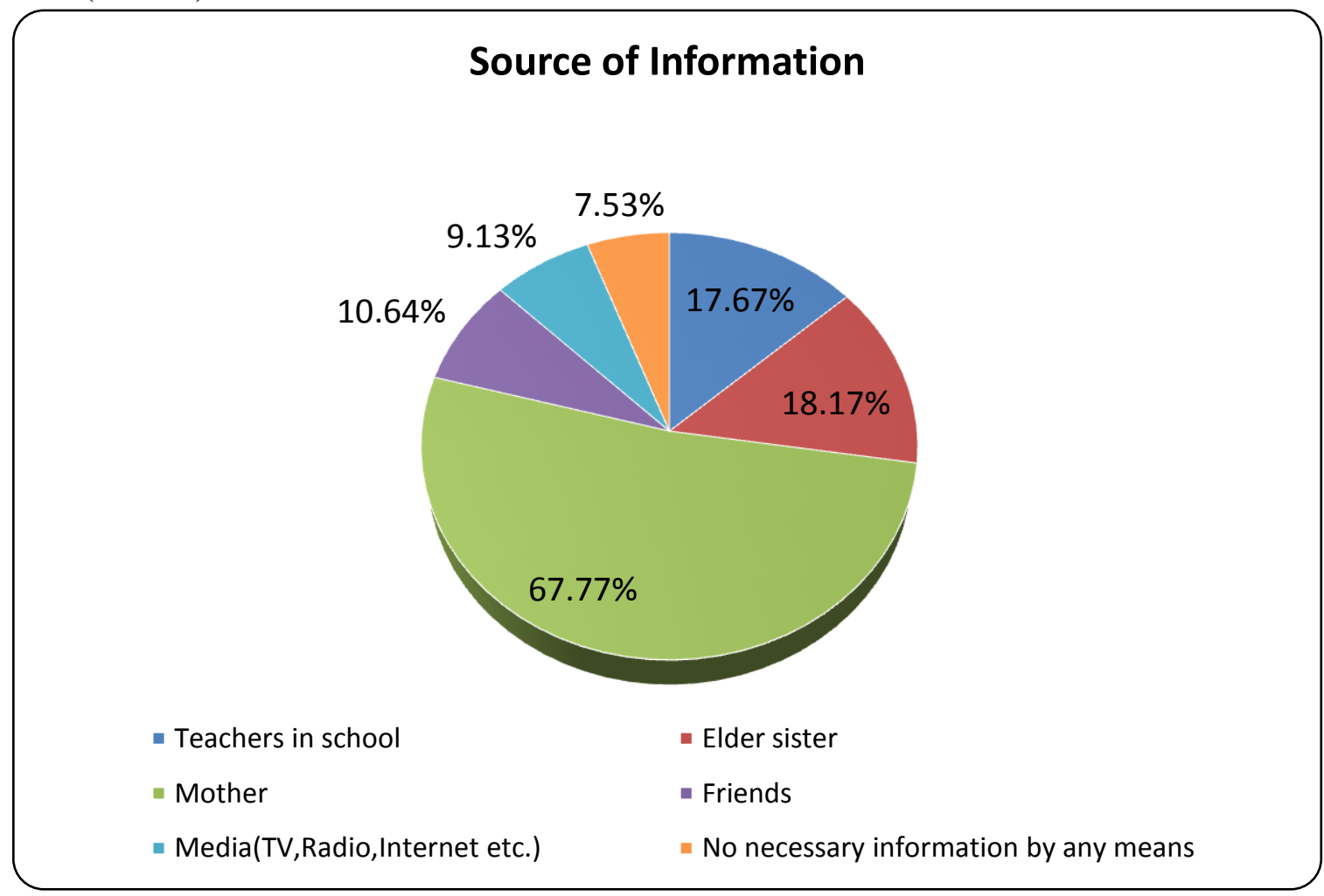

\section{Discussion}

Present study comprises 996 adolescent girls(1019 years) of class $6-12^{\text {th }}$ studying in senior secondary schools of Jaipur city. In the present study mean age of menarche of study population is $12.83+/-0.933$ years which is similar to the study done by Dasgupta et $\mathrm{al}^{(8)}$ in which the mean age of menarche of the respondents was 12.8 years whereas in a study conducted by Kollur et $\mathrm{al}^{(9)}$, in Karad, Maharashtra mean age of Menarche was found to be 13.4 years. The difference may be of difference in socio demographic profile of the participants. In the present study $80.72 \%$ participants were having prior knowledge about menstrual cycle before their menarche which was supported by the study done by Dixit et $\mathrm{al}^{(10)}$ who reported that majority of the girls $(86 \%)$ knew about menstruation before menarche occurred. In contrast study done by Ester et $\mathrm{al}^{(11)}$ in Rundu, Namibia showed that all (100\%)the girls had knowledge on menstruation before menarche. The difference may be attributed to socio-demographic and cultural difference of the participants. In the present study it was found that main source of information related to menstruation was given by mothers in majority $(67.77 \%)$ of the participants which is supported by the study done by Sanhita et $\mathrm{al}^{(12)}$ in which primary source of information about menstruation were mothers $(60.47 \%)$ teachers $(17.05 \%)$ and elder sisters $(6.20 \%)$. In contrast study among schoolgirls in Egypt by El- Gilany et $\mathrm{al}^{(13)}$ reported that mass media was the main source of information whereas in the present study only 9.13\% participants got information from mass media .The difference may be due to better mass media access by the participants in Egypt.

In the present study it was seen that $44.67 \%$ of participants reported 3-5 days duration which is less than what Dharampal $\mathrm{G}$ et $\mathrm{al}^{(14)}$ concluded in his study showing proportion of respondents who had duration of flow of 2-4 days was $67.56 \%$. However, in the present study menstrual flow duration of 5-7 days was found in $25.88 \%$ participants which was similar to the study conducted by Dharampal G et al (29.59\%). Present study revealed that $(5.8 \%)$ participants experienced longer duration of menstrual bleeding 
(>7) days and (5.4\%) reported duration of menstrual bleeding less than 3 days which is comparatively more than the study conducted by Dharampal et al who concluded that participants with duration of menstrual flow $<2$ days were $1.6 \%$ and those with menstrual flow $>8$ days were $1.25 \%$. Priyamwada et $\mathrm{al}^{(15)}$ concluded that menstrual flow duration of 3-5 days was found in $79.6 \%$ population while in present study this proportion was found to be $44.67 \%$. Duration of 5-7 days is reported by $25.88 \%$ respondents in the present study which is supported by the study done by Priyamwada et al et al (20.3\%). In present study $50.30 \%$ of girls reported cycle of 25-30 days while $6.91 \%$ had a cycle length longer than 35 days which was much less than the study done by Sudha Sharma et al ${ }^{(16)}$ in Nepal, which concluded that $23.1 \%$ respondents had cycle longer than 35 days. The difference may be due to different lifestyle, dietary habits. In the present study the most common physical complaint faced by respondents was dysmenorrheal (69.37\%) which is quite similar to the study done by Vinod Ramdasji Wasnik et $\mathrm{al}^{(17)}(69.37 \%)$ who concluded that dysmenorrhea was the most common complaint faced by participants.

In the present study $60.14 \%$ participants knew that menstruation is a natural process in which source of bleeding is uterus similar to the findings by Reena Wagh et $\mathrm{al}^{(18)}$ in which she concluded that $71 \%$ girls knew that menstruation is a physiological process and $(68 \%)$ girls knew that source of bleeding is uterus. In contrast in a study done by Ray Sudeshna et al ${ }^{(19)}$ concluded that number of respondents with correct information about source of bleeding during menstruation (uterus)was found to be only $17.9 \%$. The difference may be because participants were from rural senior secondary school. In the present study participant who were having correct knowledge regarding the concept of menstrual hygiene was only $60.04 \%$ similar to the study done by Sasmita $^{(20)}$ who concluded that $70 \%$ of the subjects had knowledge regarding concept of menstruation. In contrast study by Lawan UM ${ }^{(21)}$ et al documented that majority $(87.5 \%)$ of the participants had knowledge about the concept of menstrual hygiene. The present study concluded that $87.85 \%$ of girls had correct knowledge that readymade sanitary pads are the best absorbent to be used during menstruation which was supported by the study done by Mathiyalagen et $\mathrm{al}^{(22)}$ who concluded that sanitary pad was mentioned as ideal absorbent by $95.5 \%$ of the study population . In the present study majority of participants used sanitary pad as absorbent material exclusively followed by new cloth (13.55\%) which is supported by the study done by Kamaljit et al ${ }^{(23)}$ who reported that $69.0 \%$ of the respondents were using sanitary pads during the menstruation. In this study only $34.53 \%$ of study population changed the absorbent material every 4-5 hours which is similar to the the study done by Barthakur et $\mathrm{al}^{(24)}$ in which $35.7 \%$ changed it $\geq 3$ times a day. In contrast study done by Dixit et al (10) concluded that only $10 \%$ girls changed the absorbent thrice a day. In the present study majority of the participants practiced daily bathing (95.98\%) which is supported by study by Pagadpally $^{(25)}$ in which majority (97\%) respondents took bath daily. .On the contrary study done by Emam et al ${ }^{(26)} 32.2 \%$ girls avoid bathing during menstruation, this difference may be due to socio-cultural background of the participants. The present study concludes that $75.56 \%$ of participants followed correct practice of discarding the pad in dustbin after wrapping in paper in contrast to the study done by Hema Priya (27) et al who concluded that majority of the girls $(60.8 \%)$, burnt or buried their used menstrual absorbent. 7 percent participant of the present study flush it down in toilets and around $4.51 \%$ throw it in open spaces, which is supported by hema priya et al who also concluded that $6 \%$ girls disposed by flushing in the toilet.

\section{Conclusions and Recommendation}

The present study concluded that mothers were the major source of information of menstrual hygiene. Knowledge of using sanitary pad as 
absorbent was more than practice of using sanitary pad among participants. Dysmenorrhea was the main problem faced by the respondents. Poor practices were seen regarding frequency of changing absorbent. This study highlighted the strong need of adolescent girls to have accurate and adequate knowledge and practice of menstrual hygiene management.

As mother's are the main source of information to their children regarding knowledge on menstrual hygiene, therefore mother's of young adolescent girls can be educated with appropriate menstrual hygiene management and trained with necessary skills of communication so as to transfer the needful information to their girl child. Seminars and campaigns to improve adolescent menstrual hygiene and self care should be organized by teachers and parents association involving young adolescent girls.

\section{References}

1. WHO Adolescent health (Internet). (cited 2018 April 18,2018).Available from www.who.int/topics/adolescent_health/en.

2. Census of India Government of India, Ministry of Home Affairs, Office of the Registrar General and Census Commissioner, India. 2011(cited 2018,March 10)

3. Dambhare DG. Age at Menarche and Menstrual cycle Pattern among School Adolescent Girls in Central India. Glob J Health Sci.2012;4(1):105-11

4. Annamma Jacob, "A Comprehensive Textbook of Midwifery", $2^{\text {nd }}$ Edition, Jaypee Publications, New Delhi, 2008.Page 63.

5. House. S., Mahon T. \& Cavill S. Menstrual Hygiene Matters: A Resource for Improving Menstrual Hygiene Around the World.Wateraid.2012.257-259.

6. Oche M. O., Umar A. S. ,Gana G. J., Ango J. T. Menstrual Health: The Unmet Needs of Adolescent Girls' in Sokoto, Nigeria. Sci.Res.Essays.2012; 7 (3): 410-418.
7. Verma P,Ahmad S,Srivastava RK. Knowledge and Practices about menstrual hygiene among higher secondary school girls.Indian $\mathbf{J}$ of Community Health .2013;25(3):265-271

8. A Dasgupta,M Sarkar.Menstrual Hygiene: How Hygienic is adolescent girl?.Indian $\mathbf{J}$ Community Med. 2008;33(2): 77-80.

9. Kollur LR; Pratinidhi AK;V Kakade SV. Pubertal Changes in Adolescent Girls:A Community based Cross Sectional Study.Natl J Community Med 2013;4(4):640-3

10. Dixit S, Raghunath D, Rokade R, Nawaz SA, Nagdeve T, Goyal I.Awareness about Menstruation and Menstrual Hygiene Practices among Adolescent Girls in Central India. Ntl J Community Med 2016; 7(6):468-473.

11. Kandjimi E, Aku-Akai L.Menstrual Hygiene and School Attendance among Adolescent School Girls in Rundu. Ann Community Med Pract 2018.4(2): 1036

12. Sanhita Shyam Pokle, Aniruddha Arjun Malgaonkar, Sundaram Kartikeyan,Crosssectional interview-based study on profile of menstrual cycles and menstrual hygiene among undergraduate medical students in a metropolitan city.Int J Res Med Sci. 2016;4(11):4843-4847

13. El-Gilany AH, Badwi K, El-Fedawy S. Menstrual hygiene among adolescent schoolgirls in Mansoura, Egypt. Reprod health matters 2005;13(26):147-52.

14. Dharampal G. Dambhare,Sanjay V. Wagh, Jayesh Y. Dudhe. Age at Menarche and Menstrual Cycle Pattern among School Adolescent Girls in Central India.Glob J Health Sci. 2012;4(1): 105111.

15. Priyamvada Srivastava, Aniksha Varoda, Reeta Venugopal. Menstrual Cycle Pattern among Adolescent School Girls in Chhattisgarh. Int. J. Indian Psychol. 2016;3(3):91-8. 
16. Sudha Sharma,Sajana deuja,C.G. Saha. Menstrual pattern among adolescent girls of Pokhara Valley:a cross sectional study.BMC Women's Health.2016;16(1):1

17. Wasnik VR, Dhumale D, Jawarkar AK. A study of the menstrual pattern and problems among rural school going adolescent girls of Amravati district of Maharashtra, India. Int $\mathbf{J}$ Res Med Sci 2015;3:1252-6.

18. Reena V. Wagh, Aditi J. Upadhye, Jayshree J. Upadhye. Menstrual hygiene practices in young girls of urban India.Int J Reprod Contracept Obstet Gynecol 2018;7(5):1896-1902

19. Ray Sudeshna, Dasgupta Aparajita. Determinants of Menstrual Hygiene among Adolescent Girls: A Multivariate Analysis. Ntl J of Community Medicine .2010;3(2):294-301

20. Sasmita Ghimire,2017,Knowledge regarding menstrual hygiene among adolescent girls.Int J Res Med Sci. 2017 ;5(8):3426-3430.

21. Lawan, U. M., Nafisa, W. Y. \& Aisha, B. M. Menstruation and Menstrual Hygiene Among Adolescent School Girls in Kano, North-western Nigeria. Afr J Reprod Health.2010.14 (3): 201- 207.

22. Mathiyalagen P, Peramasamy B, Vasudevan K, Basu M, Cherian J, Sundar B. A descriptive cross-sectional study on menstrual hygiene and perceived reproductive morbidity among adolescent girls in a union territory, India. J Family Med Prim Care 2017;6:360-5

23. Kamaljit K., Balwinder Arora, Gurmeet Kahlon Singh, N.S. Neki. Social Beliefs and Practices associated with Menstrual Hygiene among Adolescent Girls of Amritsar, Punjab, India. JIMSA. 2012; 25( 2):69-71.
24. Barthakur C, Barkataki M. A Study on Reproductive Health Problems and Menstrual Hygiene Practices among Adolescent Girls Living in Slums of Guwahati city, Assam. Natl J CommunityMed 2017;8(10):602-605.

25. Pagadpally Srinivas. Perception, Knowledge and Practices Regarding Menstruation among School Going Girls in Karaikal.IOSR-JDMS.2016;15(1):27-34

26. Eman M. Mohamed, Asmaa G. Mohamed, Latifa Y. AL-Ajeal. Knowledge, beliefs and practices regarding menstruation among adolescent school girls in Seiyun city, Yemen.. AAMJ.2011;9( 3):68-86

27. Hema Priya S., Partha Nandi, Seetharaman N., Ramya M. R., Nishanthini N., Lokeshmaran A. A study of menstrual hygiene and related personal hygiene practices among adolescent girls in rural Puducherry. Int J Community Med Public Health.2017;4(7):2348-2355. 